\title{
Variantes eletroforéticos em três tribos ameríndias: Baníwa, Kanamari e Pano Central
}

Harvey Mohrenweiser ('); James V. Neel ('); M. A. Mestriner ( $\left.{ }^{2}\right) ;$ F. M. Salzano ( $\left.{ }^{3}\right)$; E. Migliazza (4); A. L. Simöes $\left({ }^{2}\right) ;$ C. Y. Yoshihara (')

\section{Resumo}

Sāo apresentados os dados sobre variantes eletroforéticos de 25 polipeptídeos séricos e eritrocitários em 812 indivíduos de 3 tribos Amerindias ( $\mathrm{Pa}$ no, Baniwa e Kanamari). Foram encontrados dois casos de polimorfismos "privados", um de PEPB nos Pano e outro de CAII nos Baníwa. Também na tribo Baníwa, foi detectada a ocorrência de um úni. co caso de uma variante diferente de PEPB e, nos Kanamari, foram encontrados dois possíveis casos de uma variante instável de HGB $\mathrm{A}_{2}$. Além disso, a variante $A$ da $A C P$, a variante Duarte da GALT, as duas variantes de $\mathrm{HP}$ e as duas variantes de PGM, apresentaram-ş em proporções polimórficas em todas as três tribos e a variante TF $\mathrm{D}_{\mathrm{Chi}}$ apresentou-se em proporçāo polimórfica nos Baníwa. Esses dados foram incorporados recentemente a um trabalho em que conclui que os oito polimorfismos eletroforéticos, definidos como "privados", encontrados em tribos ameríndias podem ser explicados por uma pressão de mutação de $0,7 \times 10^{-5} /$ locus/geração assumindo-se neutralidade dos fenótipos em questão (Thompson \& Neel, s.d.).

\section{INTRODUÇÃO}

A maioria das tribos amerídias muito próximas aos grandes rios da Bacia Amazônica Central desapareceu rapidamente após iniciados os contatos com o Velho Mundo ou, se sobreviveram, sofreram extensa mistura com neobrasileiros. A posição central dessas tribos na geografia da América do Sul Ihes atribui um especial interesse, na tentativa de reconstruir os movimentos das tribos sul-americanas e suas interrelações biológicas. No verão de 1976, foi possivel estudar uma amostra representativa de 4 dessas tribos (Pano Central, Kanamari, Baníwa e Tikuna) as quais embora relativamente aculturadas são incomuns pelo fato de terem sofrido apenas pouca ou nenhuma mistura com neobrasileiros - menor que aproximadamente $1 \% \quad$ (Neel, s.d.; Gershowitz \& Neel, s.d.). Nossos principais objetivos eram: 1) diversos estudos médicos; 2) tipagens de 13 sistemas polimórficos com o objetivo posterior de situar estes resultados dentro do complexo de relações entre os ameríndios; 3) Determinar, por técnicas eletroforéticas, a freqüência de variantes de uma série de polipeptídeos num esforço contínuo para definir a variação genética presente em uma representativa de "loci" nos ameríndios.

Em conexão com este último objetivo, um dos achados proeminentes, em estudos anteriores de tribors ameríndias feitos por nós e outros autores, foi a freqüência de polimorfismos genéticos "privados", aparentemente alelos únicos os quais, dentro de uma única tribo ou diversas tribos adjacentes, atingem freqüências gênicas bem acima de $1 \%$, estimativa esta baseada em amostras de algumas centenas de pessoas. Assim, numa aplicação sistemática de técnicas eletroforéticas para uma média de 25 proteínas em 10 tribos, foram encontrados seis casos desse fenômeno: CRPL CAY 1 (Salzano et al., 1972; Tanis et al., 1973; Neel, s. d. b), $A L B^{Y A N} 2$ (Tanis et al., 1974) ESAD MAC i (Neel et al., 1977), PEPAWAP I (Tanis et al., 1973; Neel et al., 1977), ALBMAKU (Tanis et al., 1973; Neel et al., 1977), e LDHBGUA I (Tanis et al., 1977). Dado o tipo de conhecimento da estrutura de acasalamento e demografia as quais desenvolvemos com base nos estudos de uma tribo não aculturada, os Yanomama (Neel \& Weiss, 1975; Neel, s.d. seria possível, admitindo-se certas premissas, manipular dados deste tipo com o objetivo de determinar a duraçăo do isolamento genético tribal e as taxas de mutação e pressőes seletivas consistentes com os achados.

(1) - Department of Human Genetics, University of Michigan Medical School, Ann Arbor, Michigan 48109.

(2) - Departamento de Genética, Faculdade de Medicina, Universidade de Săo Paulo, C.P. 301.

(3) - Departamento de Genética, Instituto de Biociências, Univ. Federal do Rio Grande do Sul, Porto Alegre.

(4) - Department of Anthropology, University of Maryland, College Park, Maryland 20742. 
Este trabalho se restringe aos resultados da pesquisa de variantes eletroforéticos de 25 polipeptídeos realizada em uma amostra representativa dos Baniwa, Kanamari e Pano, perfazendo um total de 812 pessoas.

\section{As TRIBOS}

BANíWA - Na época dos primeiros contatos, as margens do rio Negro eram habitadas por tribos de lingua Arawak desde sua confluência com o Solimões, formando o Amazonas, até sua cabeceira, em território Colombiano. Os Baníwa que habitam a área drenada pelo rio Içana, um tributário do rio Negro no extremo noroeste do Brasil e adjacente à Colômbia, representam um dos poucos casos daquelas tribos agora extintas. Classificados como "em permanente contato" (mas não "integrados") por Gama Malcher em 1964, poderíamos agora chamá-los de "semi-aculturados". É correntemente estimado que somam aproximadamente 1500 pessoas distribuídas em cerca de 16 vilas na área indicada na Fig. 1. Eles são organizados em 20 clãs exogâmicos patrilineares; 0 casamento preferido é com um primo cruzado paterno. Dados etnográficos podem ser encontrados em Goldman (1948), Galvão (1959, 1973) e Noble (1962). Essa tribo foi de especial interesse pois é representativa dos vizinhos a oeste dos Yanomama, entre os quais foi encontrado o polimorfismo previamente mencionado da Albumina Sérica (Tanis et al., 1974): poderia ele ter-se difundido para os Baníwa? A presente coleta foi realizada em uma pequena localidade da Missão Novas Tribos na parte superior do rio Içana, numa latitude $1^{\circ} 33^{\prime} \mathrm{N}$ e longitude $68^{\circ} 44^{\prime} \mathrm{W}$ (ver Fig. 1). A amostra foi obtida de elementos de 6 vilas, os quais foram até o local de coleta face à preleção prévia sobre o nosso programa de vacinação contra sarampo.

KANAMARí - Existem três diferentes populações referidas como Kanamarí, localizadas nas bacias dos riơs Juruá e Purus a sudoeste do Estado do Amazonas (Brasil). Elas pertencem a três grupos lingüisticos diferentes. Um, de língua Pano, é uma subdivisão dos Pano Centrais, os quais serão considerados na secção seguinte. Outro é membro de tribos de língua
Arawak localizado na parte superior do rio Purus. O terceiro grupo, objeto de nosso estudo, constitui uma tribo independente cuja língua, Katukína, não mostra relação estreita com outras línguas da área; Greenberg (1960) classificou a língua como pertencente à família Macro-Tucanovan, da qual outros componentes são representados pelos Tikuna e Tukano. Eles são uma pequena tribo estimada em um número de cerca de 800 pessoas que vivem em 9 vilas localizadas na área mostrada na Fig. 1, com uma longa história de contatos com neobrasileiros. Nossos estudos foram realizados em uma localidade da Missão Novas Tribos conhecida como Três-Unidos no Mamoré-Creek, um tributário do rio Juruá, cerca de 25 milhas aéreas a leste da cidade de Eirunepé; coordenadas aproximadas: $6^{\circ} 37^{\prime} \mathrm{S}$ e $69^{\circ} 32^{\prime} \mathrm{W}$ (ver Fig. 1). A amostra foi obtida de elementos de três vilas totalizando cerca de 130 pessoas, as quais são moradoras dessa localidade desde o estabelecimento da missão em 1967. Esta tribo nunca foi intensivamente estudada etnograficamente, sendo caracterizada por um úni-

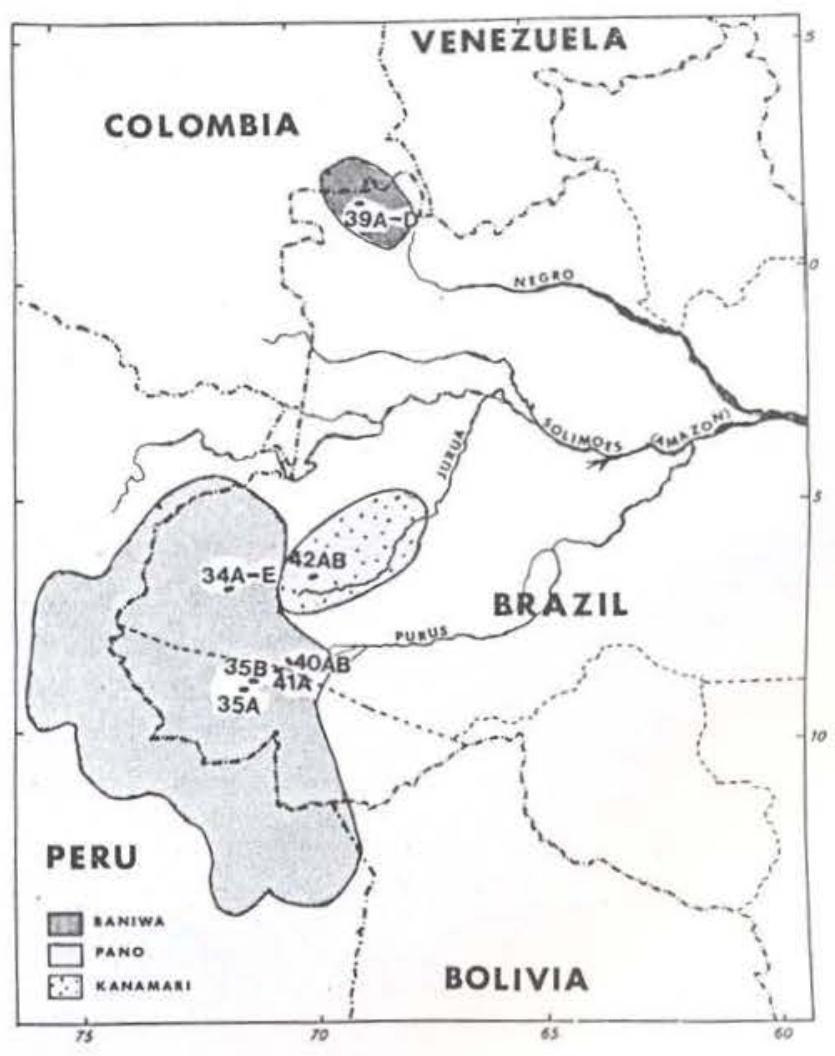

Fig. 1 - Mapa indicativo da lócalização atual das tribos e vilas. Ver texto para maiores detalhes. 
co parágrafo no trabalho de Metraux (1948) sobre tribos da bacia Juruá-Purus e é, agora, relativamente aculturada, praticando agricultura de subsistência.

PANO CENTRAL - Estes índios estāo localizados no extremo sudoeste do Estado do Amazonas e metade Oeste do Estado do Acre (Brasil) e em porçöes adjacentes do Peru. São conhecidos por, pelo menos, 15 diferentes nomes locais, cada um considerado como uma tribo diferente. A área aproximada por eles ocupada está mostrada na Fig. 1. Foram encontrados quatro grupos diferentes em cinco localidades, como mostrado na tabela 1. A análise da densidade de cognatos baseada em nossa modificação da lista de Swadesh de 200 itens (Swadesh, 1955) revelou a situação mostrada na tabela 2. O grau de inteligibilidade mútua é maior do que a que nós encontramos entre as várias subdivisỏes dos Yanomama (Spielman et al., 1974) e é a razão principal porque consideramos esses vários grupos como amostras de uma única tribo. O número total de pessoas neste grupo Pano é de 1800 aproximadamente (Kensinger, comunicação pessoal). A estrutura social de várias áreas é em geral semelhante. Por exemplo, os $\mathrm{Ma}$ rúbo (34A-E) são organizados em 9 clãs matrilineares que recebem o nome de animais. O casamento é exogâmico em relação ao clã, preferencialmente com um primo cruzado. A residência é em casa comunitária contendo elementos de dois ou mais clãs. Quando dos primeiros contatos, eram aspectos comuns de sua cultura: agricultura altamente dependente da mandioca doce e milho, cada grande familia ocupava uma grande casa, havia endocanibalismo ritual e cremação dos mortos. As principais fontes de dados etnográficos são Steward \& Metraux (1948), Steward \& Faron (1959) e Mellati \& Mellati (1975). Coincidentes com as pressões do ciclo da Borracha, um grupo de Kaxináwa relacionados àqueles que examinamos migrou para o Peru onde foram estudados por Johnston, Kensinger e cols. (veja Johnston et al., 1968, 1969) .

TABELA 1 - Dados sobre a amostra dos Pane Centrais.

\begin{tabular}{|c|c|c|c|c|}
\hline $\begin{array}{c}\text { Subdivisão } \\
\text { Pano }\end{array}$ & Nome da Vila & Coordenadas & Observaçōes & $\begin{array}{c}\text { Nossa } \\
\text { Designação }\end{array}$ \\
\hline Kaxináwa & Cana Brava & $8^{\circ} 7^{\prime} \mathrm{S}, \quad 70^{\circ} 19^{\prime} \mathrm{W}$ & $\begin{array}{l}\text { Missão Novas Tribos } \\
\text { (Subdividida em duas vilas. } \\
\text { Cana Brava e Paredão) }\end{array}$ & $40 \mathrm{~A}, \mathrm{~B}$ \\
\hline \multirow[t]{2}{*}{ Jamináwa } & $\begin{array}{l}\text { Próximo a Sete } \\
\text { Estrelas }\end{array}$ & $8^{\circ} 17^{\prime} \mathrm{S}, 71^{\circ} 34^{\prime} \mathrm{W}$ & $\begin{array}{l}\text { Vila localizada às margens do } \\
\text { rio Juruá, } 6 \mathrm{~km} \text { abaixo de } \\
\text { Sete Estrelas. }\end{array}$ & $35 \mathrm{~B}$ \\
\hline & Morada Nova & $89^{\prime} \mathrm{S}, \quad 70^{\circ} 21^{\prime} \mathrm{W}$ & $\begin{array}{l}\text { Localizada às margens do rio } \\
\text { Embira, } 2 \mathrm{~km} \text { acima de } \\
\text { Feijo. }\end{array}$ & $41 \mathrm{~A}$ \\
\hline Marúbo & Vida Nova & $6^{\circ} 47^{\prime} \mathrm{S}, 72^{\circ} 8^{\prime} \mathrm{W}$ & Missão Novas Tribos & 34 A-E \\
\hline Pano & Sete Estreias & $8^{\circ} 17^{\prime}$ 'S. $71^{\circ} 34^{\prime} \mathrm{W}$ & Missāo Novas Tribos & $35 \mathrm{~A}$ \\
\hline
\end{tabular}

TABELA 2 - Densidade de cognatos (porcentagem) nos quatri, grupos dos Pano Centrais.

\begin{tabular}{|lcccc} 
& \multicolumn{4}{c}{ Grupo } \\
\cline { 2 - 5 } Grupo & Marúbo & Pano & Jamináwa \\
Pano & 91 & & \\
Jamináwa & 33 & 85 & \\
Kaxináwa & 37 & 84 & 90
\end{tabular}

Os Pano Centrais desenvolveram extenso contato com neobrasileiros a partir do século XVII e hoje o grau de aculturação de vários subgrupos é bastante variável. Gama Malcher, em, 1964, classificou a maioria dos grupos como "integrados", mas vários deles ainda apresentavam apenas "contatos esporádicos". Desde então, os grupos estabeleceram contatos permanentes com missões ou postors go- 
vernamentais. Entre os grupos por nós estudados, os Marúbo são ainda culturalmente intactos e relativamente não aculturados, mas outros grupos vivem agora como brasileiros do interior.

\section{MÉTodos}

As amostras de sangue foram coletadas em tubos ("vacutainers" Becton-Dickinson) contendo $2 \mathrm{ml}$ de anticoagulante ACD e refrigeradas tão rápido quanto possível, geralmente dentro de 12 horas após a coleta. As amostras foram transportadas em gelo até Ann Arbor, onde o plasma e células foram estocadas a $-80^{\circ} \mathrm{C}$ ou em nitrơgênio líquido até a tipagem. As amostras foram processadas para a estocagem, geralmente, dentro de 7 dias após a coleta.

As seguintes proteínas eritrocitárias foram estudadas neste laboratório: Fosfatase Ácida - $1\left(A C P_{1}\right)$; Adenosina deaminase (ADA); Adenilato quinase - $1(\mathrm{AK})$; Anidrase Carbônica I (CA I); Anidrase Carbônica II (CAII); Galactose - 1 fosfato uridiltransferase (GALT); Hemoglobina $A_{1}(H b \propto$ e $H b \beta)$; Hemoglobina $A^{2}(A b \propto$ e $H b \beta$ ) ; Isocitrato desidrogenase $\left(\mathrm{IDC}_{\mathrm{S}}\right)$; Lactato desidrogenase $\left(\mathrm{LDH}_{\mathrm{A}}\right.$ e $\left.\mathrm{LDH}_{\mathrm{B}}\right)$; Malato desidrogenase $\left(\mathrm{MDH}_{5}\right)$; Nucleosídeo fosfarilase (NP); Peptidase A (PEPA); Peptidase B (PEPB); Fosfoglucomutase $-1\left(\mathrm{PGM}_{1}\right)$; Fosfoglucomutase - 2 $\left(\mathrm{PGM} \mathrm{M}_{2}\right)$; Fosfogluconato desidrogenase (PGD); Forfoglucose isomerase (PHI); Triosefosfato isomerase (TPI); Albumina (ALB); Ceruloplasmina (CP); Haptoglobina (HP); Transferina (TF). Além disso, as Esterases A e D foram examinadas no laboratório de Mestriner e os resultados correspondentes serão relatados em outro trabalho. Todos os métodos eletroforéticos foram previamente descritos (Tanis et al., 1973; Neel et al., 1976; Neel et al., 1977).

\section{RESULTADOS}

Nos anos recentes, com a penetração contínua de neobrasileiros nestas áreas tribais ocorreram alguns casamentos com não índios. Embora tenha sido rotina amostrá-los no cam- po, os neobrasileiros participantes destes casamentos e suas descendências foram excluidos da anáiise final. Após estas exclusōes, o número de pessoas examinadas para todos os 25 sistemas já citados foi: Baníwa, 377; Kanamarí, 100; Pano, 335 (Kaxináwa, 88; Jamináwa, 48; Marúbo, 112; Pano, 87). Foi examinado um total de 812 pessoas resultando na determinação de 40600 "loci" cxceto para os achados relacionados na tabela 3 (polimorfismo comuns) e tabela 4 (polimorfismos "privados" e variantes raros), todos os indivíduos apresentaram os fenótipos comuns para os respectivos sistemas. Os achados seião descritos em três itens :

POLIMORFISMOS COMUNS - Foram detectados em várias tribos polimorfismos bem conhecidos de cinco "loci" ( $A C P_{1}, G A L T, H P$, $P G M_{1}$ e $T F$ ) cujas freqüências gềnicas e fenotípicas são apresentadas na tabela 3 . Os pontos de interesse são os seguintes: 1) A vilas Pano exibiram uma variação intratribal com respeito aos polimorfismos da $A C P_{1}, G A L T, H P$, $P G M_{1}$, o que é característico dos ameríndios. 2) Os valores tribais com respeito a estes quatro polimorfismos estiveram dentro de uma variação característica dos ameríndiơs com exceção do alelo Duarte da GALT, o qual, em todas as três tribos, foi menos freqüente do que tem sido na maioria das tribos estudadas até agora (Neel et al., 1977; Tanis et al., 1977). 3) Foi encontrada, por eletroforese em gel de amido ou de poliacrilamida (Fig. 2a), uma variante TF com mobilidade similar à da variante $\mathrm{D}_{\mathrm{Chi}_{\mathrm{h}}}$ em uma das três tribos, Baníwa, com uma freqüência alélica de 0,016 . A variante $\mathrm{D}_{\mathrm{Chi}}$ foi descrita em diversas tribos ameríndias (Arends \& Gallango, 1964; Tanis et al., 1977) .

POLIMORFISMOS PRIVADOS - Variantes ainda não descritas de CAll e PEPB ocorreram com freqüência polimórfica nas tribos Baniwa e Pano, respectivamente. A variante CAll, nos Baniwa, foi identificada eletroforéticamente por uma migração ligeiramente menor do que a enzima CAll normal (CAll 1). A coloração foi menos intensa do que a da CAll 1 quando foi usado o diacetato de fluoresceina como substrato (Fig. 2c) . A mobilidade e intensidade de coloração também foram diferentes da 
TABELA 3 - Sistemas Polimórficos comuns,

\begin{tabular}{|c|c|c|c|c|c|c|c|c|c|c|c|c|c|c|c|}
\hline \multirow[b]{2}{*}{ Baniwa } & \multicolumn{6}{|c|}{ Hp } & \multicolumn{4}{|c|}{$\mathrm{Tl}$} & \multicolumn{5}{|c|}{$\mathrm{ACP}$} \\
\hline & 1 & $1-2$ & 2 & $\varepsilon$ & $\mathrm{Hp}{ }^{1}$ & $0^{\circ}$ & C & C-DChi & $\varepsilon$ & TFC & A & $\mathrm{AB}$ & B & $\varepsilon$ & $\mathrm{ACP}_{1} \mathrm{~B}$ \\
\hline Kanamarí & 104 & 183 & 90 & 377 & 0,519 & - & 365 & 12 & 377 & 0,948 & 6 & 43 & 328 & $\begin{array}{r}377 \\
.\end{array}$ & 0,927 \\
\hline Pano & 59 & 37 & 4 & 100 & 0,775 & - & 100 & - & 100 & - & 3 & 25 & 72 & 100 & 0,845 \\
\hline $34 \mathrm{~A} \cdot \mathrm{E}$ & 47 & 54 & 11 & 112 & 0,661 & - & 112 & - & 112 & - & 2 & 21 & 89 & 112 & 0,888 \\
\hline $35 \mathrm{~A}$ & 9 & 15 & 7 & 31 & 0,532 & 11 & 42 & - & 42 & - & 一 & 1 & 41 & . 42 & 0,988 \\
\hline $358,41 \mathrm{~A}$ & 37 & 38 & 11 & 86 & 0,651 & 7 & 93 & - & 93 & - & 1 & 6 & 86 & 93 & 0,957 \\
\hline $40 \mathrm{AB}$ & 44 & 36 & 6 & 86 & 0,721 & 2 & 88 & - & 88 & - & 1 & 5 & 82 & 88 & 0,960 \\
\hline Pano Total & 137 & 143 & 35 & 315 & 0,662 & 20 & 335 & - & 335 & - & 4 & 33 & 298 & 335 & 0,939 \\
\hline
\end{tabular}

a: Sem atividade,

\begin{tabular}{|c|c|c|c|c|c|c|c|c|c|}
\hline \multirow[b]{2}{*}{1} & \multirow{2}{*}{\multicolumn{2}{|c|}{$\frac{\mathbf{P G M}_{1}}{2}$}} & \multirow[b]{2}{*}{$\varepsilon$} & \multirow[b]{2}{*}{$\mathrm{PGB}_{1}{ }_{1}$} & \multicolumn{2}{|c|}{$\cdot$} & \multicolumn{2}{|c|}{ GALT } & \multirow[b]{2}{*}{ GALT' } \\
\hline & & & & & 1 & $1+D$ & D & $\varepsilon$ & \\
\hline 256 & 109 & 12 & 377 & 0,824 & 373 & 3 & 1 & 377 & 0,993 \\
\hline 55 & 32 & 13 & 100 & 0,710 & 97 & 2 & 1 & 100 & 0,980 \\
\hline 53 & 54 & 5 & 112 & 0,714 & 106 & 6 & - & 112 & 0,973 \\
\hline 33 & 9 & - & 42 & 0,893 & 42 & - & - & 42 & - \\
\hline 87 & 6 & - & 93 & 0,968 & 93 & - & - & 93 & - \\
\hline 87 & 1 & - & 88 & 0,994 & 86 & 2 & - & 88 & 0,989 \\
\hline 260 & 70 & 5 & 335 & 0,881 & 327 & 8 & - & 335 & 0,988 \\
\hline
\end{tabular}

TABELA 4 - Polimorfismos privados.

\begin{tabular}{|c|c|c|c|c|c|}
\hline TRIBO/PROTEINA & & & CA II & HGB & PEP B \\
\hline \multirow{2}{*}{ BANfWA } & \multirow{2}{*}{$\begin{array}{l}\text { VAKIANTES } \\
\text { TOTAL DE TIPAGENS }\end{array}$} & $\begin{array}{r}2 \\
37 \\
\end{array}$ & $\begin{array}{ll}\text { BAN } & 1 \\
\text { BAN } & 1 /+\end{array}$ & 0 & 1 BAN $1 /+$ \\
\hline & & & 377 & 377 & 377 \\
\hline \multirow{2}{*}{ KANAMARf } & \multirow{2}{*}{$\begin{array}{l}\text { VARIANTES } \\
\text { TOTAL DE TIPAGENS }\end{array}$} & \multicolumn{2}{|r|}{0} & \multirow{2}{*}{$\frac{2 \mathrm{KAN} 1 /+(?)}{100}$} & 0 \\
\hline & & & 100 & & 100 \\
\hline \multirow{2}{*}{ PANO } & \multirow[t]{2}{*}{$\begin{array}{l}\text { VARIANTES } \\
\text { TOTAL DE TIPAGENS }\end{array}$} & & $1 \mathrm{CA}$ II $2 /+$ & 0 & 16 PAN $1 /+$ \\
\hline & & & 335 & 335 & 335 \\
\hline
\end{tabular}

variante CAll 2, a qual ocorre mais freqüentemente nos negros (Fig. 2c). Embora a enzima variante tenha caracteristicas de coloração diferentes das do normalmente observado para CA, ela foi inibida pela acetazolamida (Diamox). Este inibidor é específico para CA e não tem efeito sobre a coloração de esterases (Tashian \& Carter, 1976). Assim, foi excluída a possibilidade de que a atividade fosse devida a una nova variante de esterase. A reduzida intensidade de coloração desta variante em relaçãc à enzima normai foi ainda observada após tratamento do hemolizado com alcoolclorofórmio para remover a hemoglobina (procedimento de Tashian \& Carter, 1976). A Anidrase Carbônica da amostra assim obtida, foi localizada na eletroforese em gel de amido seguida de coloração para proteína com a nigrossina. A intensidade das duas bandas de CAIl (normal e variante) foram semelhantes após a coloração com nigrosina sugerindo quantidades semelhantes de proteína (Fig. 2d).

Variantes... 
Isso poderia indicar que a atividade específica da variante CAll BAN-1 é menor do que a atividade específica tanto da CAll-1 como da CAll-2. Prosseguem outros estudos para caracterização adicional dessa variante enzimática.

Esta variante foi detectada em 39 dos 377 Baníwa; dois dos 39 não exibiram atividade CAll na posiçäo normal e são possivelmente homozigotos. Assim, a freqüência do alelo $C A l^{B A N-1}$ é 0,054 . O heredograma ilustrativo é mostrado na Fig. 3b.

Em vista da proximidade dos Baníwa e Yanomama, como pode ser notado na descrição das tribos (ver Fig. 1 e 2 em Neel et al., 1972), havia interesse em verificar a presença da variante $A L B^{Y A N-2}$ nos Baníwa, o que não foi encontrado. A descoberta da variante $C A / I^{B A N-1}$ nos Baniwa obviamente criou uma nova oportunidade para pesquisarmos evidências de trocas genéticas entre essas duas tribos. Conseqüentemente 194 indivíduos de 4 vilas Yanomama (11G, 11HI, $11 \mathrm{YZ}$ e 15QR, veja Fig. 2 em Tanis e cols., 1974, para localização das vilas) localizadas no sudoeste do território Yanomama foram triados para presença da variante CAIl ${ }^{\text {BAN-1 }}$, sendo que não foi identificado nenhum individuo portador desta variante. A variante $D_{\text {Chi }}$ da Tf também não foi detectada nos Yanomama. Estes resultados evidenciam uma relativa ausência de migraçăo intertribal.

A segunda variante em proporções polimórficas detectada nos Pano foi uma variante eletroforética de PEPB com mobilidade ligeiramente mais lenta do que a PEPB-2 previamente descrita. Esta diferença de mobilidade foi observada tanto no tampäo tris-maleato (Lewis \& Harris, 1967) (Fig. 2b) como no tampão trisfosfato (Harris \& Hopkinson, 1976) . A enzima variante e a isozima B normal apresentaram idêntica especificidade, isto é, coraram com igual intensidade quando foram usados LeuGly-Gly, Phe-Leu, Phe-Tyr e Leu-Leu-Leu como substratos. Não fơ notada nenhuma banda com mobilidade eletroforética normal ou variante PEPB quando foram utilizados substratos específicos para PEPA, PEPC, ou PEPD. O padräo eletroforético não fơi atingido quando as amostras foram incubadas na presença de $5 \mathrm{mM}$ de Ditiotreitol. Nenhuma variação foi notada na mobilidade eletroforética de PEPA, PEPC ou PEPD em indivíduos portadores da variante PEPB. Um heredograma ilustrativo é apresentado na Fig. 3a. O padrão de herança é codominante e o alelo foi designado

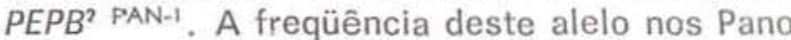
foi 0,023 , embora a distribuição entre os quatro grupos não tenha sido uniforme. A variante não foi detectada nơs Kaxináwa e, nos Pano (Katukína) localizados em Morada Nova (41A).

Entre os Jamináwa, somente 2 dos 93 indivíduos examinados (näo relacionados mas da
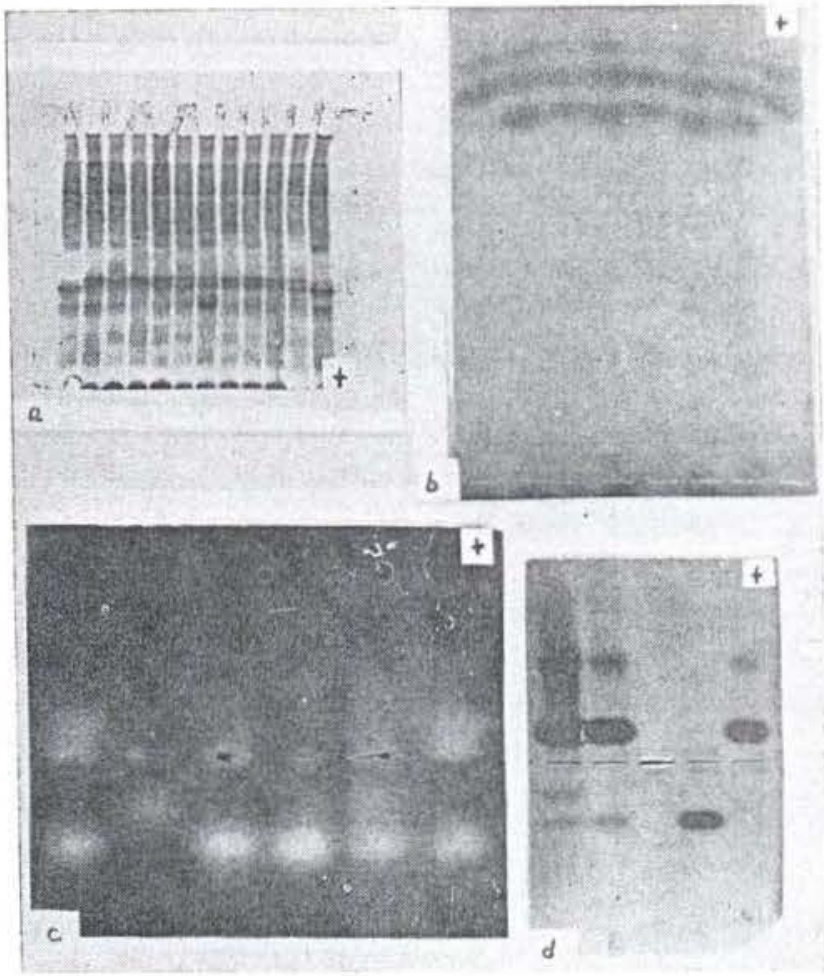

Fig. 2 - Padrão eletroforético de diversas varian. tes. a) - Transferrina: amostras 1 e 8 , tipo C; amostras 2 e $7, \mathrm{CD}_{\mathrm{Chi}}$ detectada na tribo Piaroa; amostras 3 e $8, \mathrm{CD}_{\mathrm{Chi}}$ detectada na tribo Guaymi; amostras 4 e 10, padrões normais; amostras 5, 9 e 11 são de 3 ind.uíduos Baníwa identificadas como $\mathrm{CD}_{\mathrm{Chi}}$; amostra $6, \mathrm{CD}_{\mathrm{G}_{\mu \mathrm{a}}}$; b) - Peptidase B: amostras 1 e 8, tipo 1; $\operatorname{amostras} 2,4$ e 6, tipo 1-PAN-1; amostras 6 e 7, tipo 1-2; amostra 5, tipo 1-BAN-1; c) - Anidrase carbônica II (coloração com diacetato de luoresceina): amostra 1 e 6, tipo 1-2; amostra 2, tipo BAN-í; amostras 3 e 4, tipo 1; amostra 5, tipo 1-BAN-1; d) - Anidrase carbônica (coloração com nigrosina): amostra 1, CA II tipo 1-BAN-1; amostra 2, tipo 1; amostra 3, CA II tipo purificado; amostra 4, CA I tipo 1 purificado. Amostras 1 e 2 não foram purificadas e por isso é visivel também a hemọglobina. 
mesma vila, 35B) eram portadores. A freqüência alélica foi 0,045 nos Marúbo (34A-E) e 0,048 nos Pano de Sete Estrelas (35A).

VARIANTIES RAROS - Foram encontrados três variantes raros envolvendo três diferentes sistemas. Os achados estão na tabela 4; seglie uma breve caracterização de cada um.

$\mathrm{HGB}$. Uma variante de $\mathrm{HGBA}_{2}$ foi detectada nos Kanamarí. No gel de amido original, a intensidade de coloração da banda variante foi igual à de coloração da banda na posição A2; esta última, por sua vez, foi aproximadamente metade do normal. Não foi observada nenhuma alteração no padrão de bandas por intensidade de coloração na região de $\mathrm{Hb} \mathrm{A}_{1}$, a partir do que inferimos que esta era uma variante da cadeia Delta. Não foi possível repetir esta observação. Em eletroforese, em acetato de celulose, hemolisados frescos preparados de células estocadas em nitrogênio líquido exibiram com reprodutibilidade um par de bandas de hemoglobinas anormais em uma posição catódica em relação à posição normal da $\mathrm{HGBA}_{2}$, além do padrão normal de $\mathrm{HGBA}_{2}$. A medida que o hemolisada envelhece, isto desaparece e é visto um precipitado na origem.

Uma das três crianças (sob exame) exibiu regularmente achados semelhantes na eletroforese com acetato de celulose, mas nenhuma anormalidade foi vista na eletroforese em gel de amido. Os achados permitem a hipótese da existência de uma variante instável de $\mathrm{HGB}_{2}$ o que, entretanto, não pode ser claramente comprovado. Infelizmente, as

a)
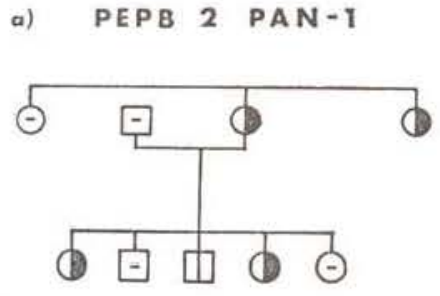

- Normal

(B) HETEROZYGOUS VARIANT

Not TESTED

Fig. 3-Hereàogramas nos quais estäo presentes algumas das variantes detectadas: a) PEPB PAN-1; b) CA II BAN-1. circunstâncias impedem a obtenção de uma nova amostra para a confirmação que um achado, como esse, requer.

PEPB. A variante de PEPB foi detectada em um único indivíduo nos Baníwa (Fig. 2d). Esta variante mostrou uma mobilidade eletroforética nos sistemas tris-maleato (Lewis \& Harris, 1967) e tris-fosfato (Harris e Hopkinson, 1976) idêntica a uma outra vista neste laboratório em populações caucasianas, a qual precisamos ser a variante PEPB2 descrita por Lewis \& Harris (1967). Tendo em vista que os sistemas genéticos $A B O$ e $G m$ não revelam evidências de mistura dos Baníwa com não-índios (Neel, no prelo), admitiu-se que esta variante não deve ter sido introduzida e, portanto, 0 alelo foi designado $P E P B^{2}$ BAN-1.

CAll. Foi detectada em um indivíduo Jamináwa uma variante de CAll a qual exibiu uma mobilidade eletroforética idêntica à da CAll 2 que ocorre em freqüências polimórficas nos negros. O sistema $A B O$ não revela nenhuma evidência de mistura não índia com a tribo, mas os grupos $\mathrm{Gm}$ sugerem um componente negro de 0,003 (Gershowitz \& Neel, no prelo). De acordo com isso, não foi designada como nova variante.

\section{Discussão}

O primeiro achado deste trabalho é a demonstração de mais dois polimorfismos eletroforéticos "privados" em tribos ameríndias relacionados com a PEPB nos Pano e a CAll nos Baníwa, elevando-se para 8 a número de tais polimorfismos inicialmente encontrados em um estudo de uma média de 25 proteínas em treze tribos (N.B.: os Kanamarí não foram incluídos no sumário de Neel, s.d., b). Além disso, encontramos um único exemplo de variante de PEPB nos Baníwa, e 2 possíveis exemplcs de uma variante instável de $\mathrm{HGBA}_{2}$ nos Kanamarí; em vista da falta de evidências de mistura não índia com estas duas tribos, achamos que essas duas variantes sejam autóctones.

A ocorrência dsse número de polimorfismos "privados" em tribos ameríndias naturalmente permite supor que sejam mantidos por forças seletivas. Em outro trabalho já demons-

Variantes... 
tramos que, em uma situação onde existe alto grau de isolamento tribal, com o passar do tempo, uma alta proporção de variantes neutros, os quais não são perdidos pelo acaso, podem assumir proporçōes polimórficas Thompson \& Neel, s.d.). Na situação comumente definida para os indios sul-americanos, os achados são consistentes com a neutralidade do fenótipo portador do mutante e com uma taxa de mutação para a variante eletroforética de $0,7 \times 10^{-5} /$ locus/geração (Thompson \& Neel, s.d.). Esta estimativa da taxa de mutação pode ser uma subestimativa por falha em detectar todos os polimorfismos privados nas tribos sob consideração. Por exemplo, embora tenhamos analisado os Pano de quatro diferen. tes localizações, os Pano do Oeste não fazem parte de nossa amostra, a qual representa apenas $1,9 \%$ de um total estimado de 18000 individuos. Os achados podem ser explicados por uma taxa de mutação concordante com as estimativas correntes das taxas de mutação no homem sem a necessidade de postular a ação de seleção positiva. As variantes poderiam ser, em certo grau, deletérias e então uma taxa de mutaçäo mais alta seria necessária para explicar a existência desses polimorfismos.

O segundo achado deste trabalho, isto é, a distribuição restrita dos polimorfismos privados, concorda com a evidência prévia de uma relativa ausência de fluxo gênico entre as tribos das bacias do Amazonas e Orinoco. A evidência disponível sugere que em tempos pré-colombianos os Yanomama e Baniwa parecem ter sido separados pelos Baré, de língua Arawak, agora reduzidos a poucas vilas remanescentes próximas do rio Negro (Loukotka, 1968). Esta tribo ainda deve ser estudada para a detecção de variantes dos sistemas pesquisados neste trabalho.

Apesar de tais estudos ainda näo terem sido realizados, os quais permitiriam afirmativas mais categóricas, já é possivel ressaltar que os movimentos intertribais naquela área nāo foram suficientes para introduzir os alelos CAl/BAN-1 e TFDehi dos Baníwa nos Yanomama, nem 0 alelo $A L B^{Y A N-2}$ dos Yanomama nos Baniwa. Estas conclusões são reforçadas quando as tribos sāo consideradas as unidades básicas das populações ameríndias.

\section{AGRADECIMENTOS}

Este trabalho foi financiado pelo contrato EY-76-C-02-2828, U. S. Energy Research and Development Administration (agora Department of Energy) e pelo Grant NSF-DEB76-20591 da National Science Foundation; e pelo Conselho Nacional de Desenvolvimento Científico e Tecnológico (Programa Integrado de Genética). Agradecemos ao Instituto Naciona! de Pesquisas da Amazônia e à Fundação Nacional do Indio pela sua ajuda. Também agradecemos o excelente apoio logístico do navio de pesquisas "Alpha Helix" da National Science Foudation. Outros participantes do trabalho de campo, cuja inestimável ajuda aqui agradecemos: Drs. Dale Lawrence, Peter Smouse, Richard Spielman, W. J. Oliver e James V. Neel Jr. e Sra. James V. Neel.

\section{SUMMARY}

Data are presented on electrophoretic variants of 25 polypeptides found in the blood serum and erythrocytes, in 812 individuals from three Amerindian trikes, the Pano, the Baniwa, and the Kanamari. Two "private polymorphisms" were encountered, of PEPB in the Pano and CAII in the Baniwa. A single example of a different PEPB variant was encountered in the Baniwa, and two possible examples of an unstable variant of HGB $\mathrm{A}_{2}$ in the Kanamari. In addition, the well-known A variant of $\mathrm{ACP}_{1}$ the Duarte variant of GALT, the 2 variant of $\mathrm{Hp}$ and the 2 variant of $\mathrm{PGM}_{1}$ occurred in polymorphic proportions in all three tribes, and the TF $\mathrm{D}_{\mathrm{Chi}}$ variant was present as a polymorphism in the Baniwa. These data have recently been incorporated into a treatment which concludes that the 8 electrophcretically-defined "private polymorphisms" thus far encountered in Amerindian tribes can be explained by a mutation pressure of $0.7 \times 10^{-5} /$ locus/generation on the assumption of neutrality of the phenotypes in question (Neel and Thompson, in press).

\section{BIBLIOGRAFIA}

Arends, T. \& Gallango, M.L.

1964 - Transferrins in Venezuelan Indians: High frequency of a slow-moving variant. Science, $143: 367368$.

GALvก̃o, E.

1959 - Aculturaçâo indígena no rio Negro. Boletim do Museu Paraense Emílio Goeldi, Nova Série, Antropologia, (7). 
GAMA MALCHER, J.M.

1964 - Indios. Conselho Nacional de Proteção aos fnçios. Publicação Viinistério da Agricultura, Rio de Janeiro, (1) : 245

Gershowitz, H. \& NEEL, J.V

s.d. - The immunoglobulin allotypes ( $\mathrm{Gm}$ and Inv) of twelve Indian tribes of Centrai and South America. Am. J. Phys, Anthrop. (No prelo)

GOLDMAN, I

1948 - Tribes of Uaupes-Caqueta region. In: Handbook of South American Indians. Washington, D.C., Smithsonian Institution. pp. 763-798

GREENBERG, J.H

1960 - The general classification of Central and South American languages. In : Men and Cultures, Selected Papers of the Fifth International Congress of Anthropological and Ethnological Sciences, Philadelphia, University of Pennsylvania Press. pp. 791-794.

HARris, H. \& HOPKINSON, D.A.

1976 - Handbook of Enzyme Electrophoresis in Human Genetics. Amsterdam. NorthHolland Publishing Co.

Johnston, F.E.; KEnSINGER, K.M.; JANTZ, R.L. \& WALKER, G.F.

1969 - The population structure of the Peruvian Casinimahua: Demographic, genetic and cultural interrelationships. Hum. Biol., $41: 20-41$

JOHNSTON, F.E.; JANTZ, R.L.; KENSINGER, K.M.; WALKIR, G.F.; ALLEN JR., F.H. \& WALKER, M.E, 1968 - Red cell blood groups of the Peruvian Cash:rahua. Hum. Biol., 40 : 508-516.

LEWIS, W.H.P. \& HARRIS, H.

1967 - Human red cell peptidases. Nature, $215: 351-355$.

Loukotka, C.

1968 - Classification of South American Indian languages. Ref. Series vol. 7. Los An geles. University of California Latin American Center, pp. 451.

Melatti, D.M. \&: MElatti, J.C.

1975 - Relatório sobre os fndios Marubo. In: Série Antropologia Social, 13. Brasil, Fundação Universidade de Brasília. p. 162 .

Métraux, A

1948 - Tribes of the Juruá-Purus Basins, In: Handibook of South American Indians, 3. Smithsonian Institution, Bulletin, 143. Washington, D.C. pp. 657-712
NEEL, J.V.

s.d.a - The population structure of an Amerindian tribe, the Yanomama. Ann. Rev. Genetics, (no prelo).

s.d.b - Rare variants, private polymorphisms, and locus heterozygosity in Amerindian populations. Am. J. Hum. Genet., (no prelo).

Neel, J.V.; Arends, T.; Brewer, C.; Chagnon, N.; Gershowitz, H.; LAyrisse, M.; LAyrisse, Z.; MACCluer, J.; Migliazza, 巴.; Oliver, W.; Salzano, R.; Spielman, R.; WARD, R, \& WeITKAMP, L.

1972 - Proceedings, IV Int. Cong. Hum. Genet. Paris, 1971. Excerpta Medica, Amsterdam. pp. 96-111.

Neel, J.V.; Ferrell, R.E. \& Conard, R.A.

1976 - The frequency of "rare" protein variants in Marsnall islanders and other Micro. nesians. Am. J. Hum. Genet., 28:262-269.

Neel, J.V.; Tanis, R.J.; Migliazza, E.C.; Spielmai, R.S.; Salzano, F.; OltVer, W.J.; Morrow, M. is BACHOFER, S.

1977 - Genetic studies of the Macushi and Wapishana Indians. I. Rare genetic variants and a "private polymorphism" of esterase. A. Hum, Genet., 36:81-107.

Oliveira, Adélta E. de \& Galvão, E.

1973 - A situação atual dos Baniwa (Alto rịc Negro) - 1971. In: O Museu Goeldi no Ano do Sesquicentenário. Publicações Avulsas do Museu Goeldi, Belém, 20 : $27-40$.

Spielman, R.S.; Migliazza, E.C. \& NeEl, J.V

1974 - Regional linquistic and genetic differences among Yanomam Indians. Science $184: 637-644$.

STEWARD, J.H. \& FARON

1959 - Native peoples of South America. New York, McGraw-Hill. pp. 555-595.

Steward, J.H. \& Métraux, A

1948 - Tribes of the Peruvian and Ecuadorian Mont๘ña. In: Handbook of South American Indians, v. 3. Smithsonian Institution, Bullerin, 143. Washington, D.C., GPO. pp. 535-656.

SWADESH, M.

1955 - Towards greater accuracy in lexicosta tistic dating. Int. J. Am. Linguistics, $21: 121-137$

TANis, R.J.; Ferrell, R.E.; NeEl, J.V. \& Morrow, M. 1974 - Albumin Yanomama-2, a "private" polymorphism of serum albumin. Ann. Hum Genet., London, 38 : 179-190. 
TANIS, R.J.; NEEL, J.V. \& ARAUZ, R.T. DE

1977 - Two more "private" polymorphisms of Amerindian tribes: LDH GUA 1 and $A C P_{1} B_{G U A_{1}}$ in the Guaymi of Panama. Am. J. Hum. Genet., $29: 419-430$.

TANiS, R.J.; NeEl, J.V.; DOvey, H. \& Morrow, M. 1973 - The gemetic structure of a tribal population, the Yanomama Indians. IX, Gene frequencies for 18 serum protein and erythrocyte enzyme systems in the Yanomama and five neighboring tribes; nine new variants. Am. J. Hum. Genet., $25: 655-676$.
TASHAN, R.E. \& CARTER, N.D

1976 - Biocnemical genetics of carbonic anhy. drase, Adv. Hum. Genet., $7: 1-56$

THOMPSON, E.A. \& NEEL, J.V

s. d. - The probability of founder effect in 3 tribal population. Proc. Nat. Acat. Sei., U.S.A. (No prelo)

(Aceito para publicaçāo em 27/02/ ซٔ) 